\title{
Comparative analysis of microsatellite variability in five macaw species (Psittaciformes, Psittacidae): Application for conservation
}

\author{
Flavia T. Presti ${ }^{1}$, Adriana R. Oliveira-Marques ${ }^{1}$, Renato Caparroz $^{2}$, Cibele Biondo ${ }^{3}$ and Cristina Y. Miyaki ${ }^{1}$ \\ ${ }^{1}$ Departamento de Genética e Biologia Evolutiva, Instituto de Biociências, Universidade de São Paulo, \\ São Paulo, SP, Brazil. \\ ${ }^{2}$ Departamento de Biologia Geral, Instituto de Ciências Biológicas, Universidade Federal de Goiás, \\ Campus II Samambaia, Goiânia, GO, Brazil. \\ ${ }^{3}$ Departamento de Ecologia, Instituto de Biociências, Universidade Estadual Paulista \\ "Júlio de Mesquita Filho", Rio Claro, SP, Brazil.
}

\begin{abstract}
Cross-amplification was tested and variability in microsatellite primers (designed for Neotropical parrots) compared, in five macaw species, viz., three endangered blue macaws (Cyanopsitta spixii [extinct in the wild], Anodorhynchus leari [endangered] and Anodorhynchus hyacinthinus [vulnerable]), and two unthreatened red macaws (Ara chloropterus and Ara macao). Among the primers tested, $84.6 \%$ successfully amplified products in C. spixii, $83.3 \%$ in A. leari, $76.4 \%$ in $A$. hyacinthinus, $78.6 \%$ in $A$. chloropterus and $71.4 \%$ in $A$. macao. The mean expected heterozygosity estimated for each species, and based on loci analyzed in all the five, ranged from $0.33(A$. hyacinthinus) to 0.85 ( $A$. macao). As expected, the results revealed lower levels of genetic variability in threatened macaw species than in unthreatened. The low combined probability of genetic identity and the moderate to high potential for paternity exclusion, indicate the utility of the microsatellite loci set selected for each macaw species in kinship and population studies, thus constituting an aid in planning in-situ and ex-situ conservation.
\end{abstract}

Key words: conservation, cross-amplification, macaw, microsatellite, Psittaciformes.

Received: August 13, 2010; Accepted: December 23, 2010.

Around $30 \%$ of all parrot species are endangered or vulnerable due to habitat destruction and illegal trade (Collar, 1997). Conservation may include the establishment of ex-situ populations for reproduction programs, as well as in-situ management (e.g. translocation and reintroduction). Microsatellite data constitute a useful aid in planing the estimation of genetic relationships among individuals, demes and populations, as well as in the analysis of genetic variability and population dynamics (Jarne and Lagoda, 1996; Ellegren et al., 1997; Li et al., 2002). Moreover, these markers can be employed in guiding breeding decisions and improving the genetic management of captive populations, through the identification of potential couples with the lowest genetic similarities (Caballero and Toro, 2000; Jones et al., 2002; Russello and Amato, 2004). However, the isolation of microsatellite loci is usually expensive and time-consuming. Furthermore, the avian genome contains about 10 times less microsatellite loci than is the case with humans (Primmer et al., 1997). As an alternative, these

Send correspondence to Flavia T. Presti. Departamento de Genética e Biologia Evolutiva, Instituto de Biociências, Universidade de São Paulo, Rua do Matão 277, 05508-090 São Paulo, SP, Brazil. E-mail: flapresti@ hotmail.com. primers from closely related species can be cross-amplified in the focal organism (Primmer et al., 2005).

Few microsatellite markers have been developed for parrots, although positive cross-amplification of some has been reported for several species (Hughes et al., 1998; Robertson et al., 2000; Russello et al., 2001, 2007; Caparroz et al., 2003, 2007; Sainsbury et al., 2004; Chan et al., 2005; Raisin et al., 2009; Pillay et al., 2009). Nevertheless, there is no available information regarding amplification efficiency or polymorphism levels in several macaw species.

The aim was to report the success in cross-species amplification of several microsatellite markers, and in the comparative analysis of polymorphism levels in five macaw species, three endangered (the Spix's macaw, Cyanopsitta spixii, extinct in the wild, the Lear's macaw, Anodorhynchus leari, endangered, and the hyacinth macaw, Anodorhynchus hyacinthinus, vulnerable), as well as two unthreatened species (the scarlet macaw, Ara macao, and the red-and-green macaw, $A$. chloropterus).

Blood samples were analyzed from 11 captive Spix's macaws (eight originally from the wild, and three nonsiblings born in captivity), 21 captive Lear's macaws (although all wild birds, their geographical origin and rela- 
tionships were unknown), 30 wild hyacinth macaws from the Pantanal (state of Mato Grosso do Sul), 31 wild redand-green macaws from the Pantanal, and 28 wild scarlet macaws from the southeast of the state of Pará, all in Brazil. Samples of the latter three species were obtained from nestlings. Only one chick per nest was studied. All the samples were preserved in absolute ethanol and stored frozen at the Laboratório de Genética e Evolução Molecular de Aves (LGEMA), Instituto de Biociências, Universidade de São Paulo. Total DNA was extracted from blood samples, according to standard protocol, with proteinase $\mathrm{K}$ digestion and phenol: chloroform (Bruford et al., 1992).

Primer pairs were tested for 19 di- and tetranucleotide microsatellite loci. Seven of these were designed for Ara ararauna (UnaCT21, UnaCT32, UnaCT43, UnaCT74 and UnaGT55; Caparroz et al., 2003; UnaCT41int; Gebhardt and Waits, 2008; UnaCT35 F 5'TCTATCCCTTTTTGTC AGC3' and UnaCT35 R 5'TAGCTAGATTTTCTTCTC TG3'; R. Caparroz, unpublished), eight for Amazona guildingui (AgGT07, AgGT08, AgGT12, AgGT17, AgGT21, AgGT81, AgGT19 and AgGT32; Russello et al., 2001, 2005), two for Anodorhynchus hyacinthinus (Scott K. Davis, unpublished; MAC 436 F 5'GCACCAAACA CAACATCTTATTC3' and MAC 436 R 5'TTGGGACAC CAATGTAATTTG3', and HYA 1172 F 5'GATCCTTTG CTTAAGACAGATGTC3' and HYA 1172 R 5'GAGTGAAATACACATTCAGCTTCTG3'), and two for Psittacus erithacus (Pee $\mu 11$ and Pee $\mu 16$; Taylor and Parkin, 2007). In each primer pair, the forward one had an additional 5' M13 sequence tail (5'-TGTAAAACGACG GCCAGT-3') (Schuelke, 2000), so as to enable applying the universal dye-labelling method (Boutin-Ganache et al., 2001).

We initially tested the potential cross-amplification of each locus (Table 1) with two to four samples from each species. PCR was carried out in a total volume of $12 \mu \mathrm{L}$ with 20-50 ng of template DNA, $10 \mathrm{mM}$ of Tris- $\mathrm{HCl}$, $50 \mathrm{mM}$ of $\mathrm{KCl}, 1.5 \mathrm{mM}$ of $\mathrm{MgCl}_{2}, 200 \mu \mathrm{M}$ of each dNTP, $0.2 \mu \mathrm{M}$ of a M13 fluorescent primer (FAM, HEX or NED, Applied Biosystems, CA), $0.1 \mu \mathrm{M}$ of an M13 tailed forward primer, $0.3 \mu \mathrm{M}$ of a reverse primer and 0.5 unit of $\mathrm{Taq}$ polymerase (Pharmacia). PCR conditions were: initial denaturation at $95{ }^{\circ} \mathrm{C}$ for $10 \mathrm{~min}$; followed by 35 cycles of $95^{\circ} \mathrm{C}$ for $1 \mathrm{~min}, 52-58^{\circ} \mathrm{C}$ (see Table 1 ) for $40 \mathrm{~s}$ and, $72{ }^{\circ} \mathrm{C}$ for $40 \mathrm{~s}$; and a final extension of $72^{\circ} \mathrm{C}$ for $7 \mathrm{~min}$. Amplification products were visualized in $1.5 \%$ agarose gel and fragments sized by comparison with the $1 \mathrm{~kb}$ Plus DNA ladder (Invitrogen). Any amplification that produced fragments with similar sizes to those observed in source species was considered successful. Allele sizes were determined on an ABI 377 DNA sequencer (Applied Biosystems) for blue macaws, and a MegaBACE 1000 (GE Healthcare) for red macaws, using a weight standard (TAMRA 500C or GeneScan -500 ROX STANDARD, Applied Biosystem) in 
each sample lane. Profile analysis was undertaken with GeneScan and Genotyper 2.1 (Applied Biosystems), or MegaBACE Genetic Profiler Software Suite v2.2 (GE Healthcare). A fragment from one homozygous individual from each species was also sequenced, using the Big Dye Terminator Cycle Sequencing Kit (Applied Biosystems), to check for the presence of microsatellite loci.

The number of alleles per locus, observed and expected heterozygosities (Nei, 1978), paternity exclusion (Q, Weir, 1996) and genetic identity probabilities (Paetkau et al., 1995) were estimated using Identity 1.0 (Wagner and Sefc, 1999). Deviation from Hardy-Weinberg expectation and linkage equilibrium were analyzed with Genepop 4.0 (Raymond and Rousset, 1995), and by applying the Bonferroni correction to account for multiple comparisons. Genotyping errors, due to null alleles, stutter bands or allele dropouts, were analyzed using Micro-checker 2.2.3 (van Oosterhout et al., 2004).

Among the heterologous primer pairs tested, eleven of thirteen (84.6\%) amplified products in the Spix's macaw, 10 of $12(83.3 \%)$ in the Lear's, 13 of $17(76.4 \%)$ in the hyacinth, 11 of $14(78.6 \%)$ in the red-and-green and 10 of 14 (71.4\%) in the scarlet macaw (Table 1). Sequencing results showed that the repeat units are the same as those in source species. Among these successfully amplified loci, six were polymorphic in the Spix's $(54.5 \%)$ and Lear's macaws $(60 \%)$, eleven in the hyacinth $(84.3 \%)$, and ten in the red-and-green (90.9\%) and scarlet (100\%). The number of alleles per polymorphic locus ranged from two to five in the Spix's macaw, two to six in the Lear's macaw, two to seven in the hyacinth, two to 12 in the red-and-green, and five to 15 in the scarlet (Table 1).

All the pairs of polymorphic loci were in linkage equilibrium in all the species studied. Sporadic cases of departure from Hardy-Weinberg equilibrium (HWE, $p<0.01$ ) were found in the blue macaw species: locus UnaCT43 in the Spix's; UnaCT35 and MAC436 in the Lears; and MAC436, UnaCT41 ${ }_{\text {int }}$, and Pee $\mu 11$ in the hyacinth macaw (Table 2). Analysis with Micro-Checker software revealed null alleles at all these loci. Expected heterozygosity across all the loci in Hardy Weinberg equilibrium were 0.55 in the Spix's macaw, 0.62 in the Lear's, 0.40 in the hyacinth, 0.55 in the red-and-green, and 0.74 in the scarlet (Table 2).

Threatened species, usually present in small populations, are more vulnerable to loss of genetic diversity through processes such as genetic drift and inbreeding. Thus, it was expected that levels of genetic variability in the threatened species studied would be lower than in the unthreatened. This proved to be so, results showing lower levels of genetic variability in the threatened blue macaws than in the unthreatened red. On considering only the four loci UnaCT21, UnaCT43, UnaCT74 and AgGT21, which successfully amplified in all the species, expected mean heterozygosis in the three blue macaws proved to be lower than in the two red (Table 2). Furthermore, monomorphic 
loci were more frequently observed in the former. This is in accordance with results from DNA fingerprinting, showing a certain correlation between genetic similarity among pairs of individuals and the level of threat. In the extinct Spix's macaw, the similarity is $64 \%$ (Caparroz et al., 2001b), in the vulnerable hyacinth, 34\% (Miyaki C. Y., unpublished results), and in the unthreatened red-and-green, 27\% (Caparroz et al., 2001a). Moreover, 21 single locus minisatellite markers also showed higher variability in red-and-green macaws than in the hyacinth (Faria and Miyaki, 2006).

The Spix's macaw, already rare since its discovery, is now extinct in the wild (Ridgely, 1981, Sick, 1981). Although most of the Spixs samples analyzed were from wild individuals, given the rarity of the species, they are all possibly related, a possible reflection of its historically small wild population.

In 2003, the population of Lear's macaws was estimated to be around 450 individuals (Menezes et al., 2006). This species occurs in a small area in the state of Bahia (Brazil). As most likely all the individuals analyzed here came from this very same, small wild population, the low genetic variability levels observed here could be thus related. However, as the relationships among these individuals are unknown, it is possible that genetic variability levels are biased, due to possible kinship among some.

The population of the hyacinth is the largest among the blue macaws. It is estimated to be around 6,500 individuals, with 5,000 in the Pantanal alone (Birdlife International, 2010). However, its mean expected heterozygosity has proved to be relatively low, compared to that estimated for each of the other two more threatened blue species (Table 2). All the individuals analyzed, although possibly not closely related (only one chick per nest was studied), were sampled in the same area, most likely from the same population. Thus, this sampling appears to be a reliable representation of the wild population in the Pantanal. Even so, the analysis of individuals from other localities is essential for characterizing the genetic variability of the species, as a whole.

The total population sizes of both red macaws studied here is unknown, but it is not believed to approach the thresholds of vulnerability under the population-size-criterion of the International Union for Conservation of Nature $(<10,000$ mature individuals with a continuing decline estimated to be $>10 \%$ in ten years or three generations, or with a specified population structure; Birdlife International, 2000). Thus, it becomes essential to expand their geographical sampling, in order to evaluate the variability levels in the two species.

On considering all the loci, the potential of paternity/maternity exclusion was greater than $78 \%$ in all the macaw species studied (Table 2). It is noteworthy that in the case of red macaws the potential was more than $99 \%$, thus indicating the suitability of these loci for parentage testing.
This study placed in evidence that, in the macaw species analyzed, the cross-amplification of previously developed microsatellite loci can increase the availability of markers to address both ecological and population questions. The low combined-probabilities of genetic identity, and the moderate to high probabilities of paternity exclusion (Table 2), indicate the utility of these microsatellite sets in studying parentage and population differentiation, a valuable aid in planning in-situ and ex-situ conservation action.

\section{Acknowledgments}

We wish to thank the Instituto Brasileiro do Meio Ambiente e dos Recursos Naturais Renováveis, Instituto Chico Mendes de Conservação da Biodiversidade, Rio de Janeiro and São Paulo Zoos, Projeto Arara-azul-de-lear, and Loro Parque Fundación for providing samples. This work was funded by the Fundação de Amparo à Pesquisa do Estado de São Paulo (FAPESP), Coordenação de Aperfeiçoamento de Pessoal de Nível Superior (CAPES), and Conselho Nacional de Desenvolvimento Científico e Tecnológico (CNPq).

\section{References}

BirdLife International (2000) Threatened Birds of the World, $1^{\text {st }}$ ed. Lynx Edicións and Birdlife International, Barcelona, 864 pp.

Boutin-Ganache I, Raposo M, Raymond M and Descepper CF (2001) M13-tailed primers improve the readability and usability of microsatellite analyses performed with two different allele-sizing methods. Biotechniques 31:1-3.

Bruford MW, Hanotte O, Brookfield JFY and Burke T (1992) Single locus and multilocus DNA fingerprinting. In: Hoelzel CAR (ed) Molecular Genetic Analyses of Populations: A Practical Approach. Oxford University Press, New York, pp 225-269.

Caballero A and Toro MA (2000) Interrelations between effective population size and other pedigree tools for the management of conserved populations. Genet Res 75:331-343.

Caparroz R, Guedes NMR, Bianchi CA and Wajntal A (2001a) Analysis of the genetic variability and breeding behaviour of wild populations of two macaw species (Psittaciformes: Aves) by DNA fingerprinting. Ararajuba - Rev Bras Ornitol 9:43-49.

Caparroz R, Miyaki CY, Bampi MI and Wajntal A (2001b) Analysis of the genetic variability in a sample of the remaining group of Spixs Macaw (Cyanopsitta spixii, Psittaciformes: Aves) by DNA fingerprinting. Biol Conserv 99:307-311.

Caparroz R, Miyaki CY and Baker AJ (2003) Characterization of microsatellite loci in the blue-and-gold macaw, Ara ararauna (Psittaciformes, Aves). Mol Ecol Notes 10:1046-1048.

Caparroz R, Leite KCE, Chinalia LA, Miyaki CY and Collevatti RG (2007) Characterization of microsatellite loci in three species of Amazona (Psittaciformes) using heterologous primers. Ornitol Neotrop 18:438-444.

Chan C, Ballantyne KN, Lambert DM and Chambers GK (2005) Characterization of variable microsatellite loci in Forbes' 
parakeet (Cyanoramphus forbesi) and their use in other parrots. Conserv Genet 6:651-654.

Collar NJ (1997) Family Psittacidae (Parrots). In: Del Hoyo J, Elliot A and Sargatal J (eds) Handbook of the Birds of the World, vol.4, Lynx Edicións, Barcelona. pp 280-477.

Ellegren H, Lindgren G, Primmer CR and Möller AP (1997) Fitness loss and germline mutations in barn swallows breeding in Chernobyl. Nature 389:593-596.

Faria PJ and Miyaki CY (2006) Molecular markers for population genetic analyses in the family Psittacidae (Psittaciformes, Aves). Genet Mol Biol 29:231-240.

Gebhardt KJ and Waits LP (2008) Cross-species amplification and optimization of microsatellite markers for use in six neotropical parrots. Mol Ecol Resour 4:835-839.

Hughes CR, Meland RR and Beissinger SR (1998) Polymorphic trinucleotide microsatellite loci for neotropical parrot, the green-rumped parrotlet, Forpus passerinus. Mol Ecol 7:1247-1248.

Jarne P and Lagoda PJL (1996) Microsatellite, form molecules to populations and back. Trends Ecol Evol 11:424-429.

Jones KL, Glenn TC, Lacy RC, Pierce JR, Unruh N, Mirande CM and Chavez-Ramirez F (2002) Refining the whooping crane studbook by incorporating microsatellite DNA and legbanding analyses. Conserv Biol 16:789-799.

Li YC, Korol AB Fahima T, Beiles A and Nevo E (2002) Microsatellites: Genomic distribution, putative functions and mutational mechanisms: A review. Mol Ecol 11:2453-2465.

Menezes AC, Araujo HFP, Nascimento JLX, Rego ACG, Paiva AA, Serafim RN, Bella SD and Lima PC (2006) Monitoramento da população de Anodorhynchus leari (Bonaparte, 1856) (Psittacidae) na natureza. Ornithologia 1:105-167. (Abstract in English)

Nei M (1978) Estimation of average heterozygosity and genetic distance from a small number of individuals. Genetics 89:583-590.

Paetkau D, Calvert W, Stirling I and Strobeck C (1995) Microsatellite analysis of population structure in Canadian polar bears. Mol Ecol 4:347-354.

Pillay K, Dawson DA, Horsburgh GJ, Perrin MR, Burke T and Taylor TD (2009) Twenty-two polymorphic microsatellite loci aimed at detecting illegal trade in Cape parrot, Poicephalus robustus (Psittacidae, Aves). Mol Ecol Resour 10:142-149.

Primmer CR, Raudsepp T, Chowdhary BP, Möller AP and Ellegren $H$ (1997) Low frequency of microsatellites in the avian genome. Genome Res 7:471-482.

Primmer CR, Painter JN, Koskinen MT, Palo JU and Merilä J (2005) Factors affecting avian cross-species microsatellite amplification. J Avian Biol 36:348-360.

Raisin C, Dawson DA, Greenwood AG, Jones CG and Groombridge JJ (2009) Characterization of Mauritius parakeet (Psittacula eques) microsatellite loci and their cross-utility in other parrots (Psittacidae, Aves). Mol Ecol Resour 9:1231-1235.

Raymond M and Rousset F (1995) GENEPOP (version 1.2): Population genetic software for exact tests and ecumenicism. J Hered 86:248-249.
Ridgely RS (1981). The current distribution and status of mainland Neotropical parrots. In: Pasquier RF (ed) The Conservation of New World Parrots. ICBP Parrot Working Group Meeting (Technical Publication 1). Smithsonian Institution Press, Sta Lucia, pp. 241-242.

Robertson BC, Minot EO and Lambert DM (2000) Microsatellite primers for the kakapo (Strigops habroptilus) and their utility in other parrots. Conserv Genet 1:93-95.

Russello M, Calcagnotto D, DeSalle R and Amato G (2001) Characterization of microsatellite loci in the endangered St. Vicent Parrot, Amazona guildingii. Mol Ecol Notes 1:13-15.

Russello MA and Amato G (2004) Ex situ population management in the absence of pedigree information. Mol Ecol 13:2829-2840.

Russello MA, Lin K, Amato G and Caccone A (2005) Additional microsatellite loci for endangered St. Vincent Parrot, Amazona guildigii. Conserv Genet 6:643-645.

Russello MA, Saranathan V, Buhrman-Deever S, Eberhard J and Caccone A (2007) Characterization of polymorphic microsatellite loci for the invasive monk parakeet (Myiopsitta monachus). Mol Ecol Notes 7:990-992.

Sainsbury JP, Macavoy E and Chambers GK (2004) Characterization of microsatellite loci in the Kaka, Nestor meridionalis. Mol Ecol Notes 4:623-625.

Schuelke M (2000) An economic method for the fluorescent labeling of PCR fragments. Nat Biotechnol 18:233-234.

Sick H. (1981). About the blue macaws, especially the Lear's Macaw. In: Pasquier RF (ed) The Conservation of New World Parrots. ICBP Parrot Working Group Meeting (Technical Publication 1). Smithsonian Institution Press, Sta Lucia, pp. 439-444.

Taylor TD and Parkin DT (2007) Characterization of 12 microsatellite primers pairs for the African grey parrot, Psittacus erithacus and their conservation across the Psittaciformes. Mol Ecol Notes 7:163-167.

van Oosterhout C, Hutchinson WF, Wills DPM and Shipley P (2004) MICRO-CHECKER: software for identifying and correcting genotyping errors in microsatellite data. Mol Ecol Notes 4:535-538.

Weir BS (1996) Genetic Data Analysis II - Methods for discrete population genetic data. Sinauer Associates, Sunderland, $376 \mathrm{pp}$.

\section{Internet Resources}

BirdLife International (2010) Anodorhynchus hyacinthinus. In: IUCN 2010. IUCN Red List of Threatened Species. Version 2010.1. http://www.iucnredlist.org (October 25, 2010).

Wagner HW and Sefc KM (1999) Identity 1.0. Centre for Applied Genetics, University of Agricultural Science, Vienna, http:www.boku.ac.at/zag/forsch/MANUAL.doc (October $25,2010)$.

\section{Associate Editor: Louis Bernard Klaczko}

License information: This is an open-access article distributed under the terms of the Creative Commons Attribution License, which permits unrestricted use, distribution, and reproduction in any medium, provided the original work is properly cited. 